\title{
Association of Gender, Triglyceride/HDL Ratio, and Physical Activity of Obese Adolescents in Makassar
}

\author{
Nurhaedar Jafar ${ }^{1 \star}$, Aminuddin Syam ${ }^{1}$, Yessy Kurniati ${ }^{2}$, Een Kurnaesih ${ }^{3}$, Reza Aril Ahri $^{3}$, Nurlela Jamaluddin ${ }^{3}$ \\ ${ }^{1}$ Nutrition Study Program, Faculty of Public Health, Hasanuddin University, Makassar, Indonesia; ${ }^{2}$ Public Health Study Program, \\ Faculty of Medicine and Health Science, Islamic State University of Alauddin, Makassar, Indonesia; ${ }^{3}$ Department of Health \\ Administrationa, Faculty of Public Health, Muslim University of Indonesia, Makassar, Indonesia
}

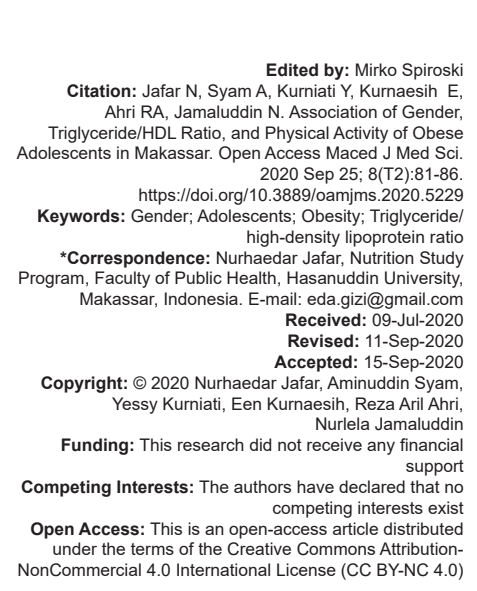

Abstract

BACKGROUND: Obesity may cause the increase of triglyceride and decrease of high-density lipoprotein (HDL) levels. Triglyceride/HDL ratio is associated with metabolic disorders. Physical activity is one of the important aspects in preventing obesity. Gender is known to have a relationship with these factors, but it has been inconsistent.

AIM: This study aimed to evaluate the relationship between sex and triglycerides, levels of HDL, triglycerides/HDL ratio, and physical activity of obese adolescents in Makassar.

METHODS: This study used a cross-sectional design involving 93 samples of obese adolescents from three high schools. Measurement of triglyceride and HDL levels was performed by the Prodia laboratory, while physical activity was measured using the International Physical Activity Questioner. Data analysis was performed with Chi-square and Fisher's exact tests.

RESULTS: The results showed that there is a relationship between gender and triglyceride levels $(p=0.006)$ and $\operatorname{HDL}(p=0.034)$, but no relationship between the ratio of TG/HDL $(p=0.109)$ and physical activity was found $(p=$ 0.339).

CONCLUSION: Efforts should be made to reduce the level of risk adolescent obesity on the risk of metabolic syndrome and cardiovascular disease, including increase physical activity. Physical activity is important to maintain the physical and mental of obese adolescents.

\section{Introduction}

Some studies have shown the association of gender with obesity. Male and female may have differences in exposure to the obesogenic environment. The difference is probably due to biological and psychosocial factors. Biological factors, such as sex hormones, cause one sex to have a greater risk of becoming obese. Involvement in physical activity, as one of the factors the risk of obesity, can also make any differences in response to the obesogenic exposures.

However, various studies have been conducted to examine obesity in adolescents showing that men and women have the same possibility to dominate the incidence of obesity in a region. Studies involving teenagers in an international sample found that adolescent obesity rates are higher in males than females. Another study found that the incidence of obesity was higher in women [1], [2], [3]. However, the difference was not significant [4]. A study conducted in Europe in 1990 found a number of countries to have almost the same prevalence of overweight and obesity in men and women, meaning that young men and young women have the same risk of obesity [5].

Obesity causes increased triglyceride levels and decreased high-density lipoprotein (HDL) levels [6]. Triglycerides are glycerides in which glycerol is esterified with three fatty acids. The main function of triglycerides is as an energy reserve. HDL is the smallest and most density lipoprotein. HDL contains the largest proportion of protein for cholesterol. HDL plays an important role in the synthesis of steroid hormones and protection against cardiovascular disorders. Obese adolescents have high triglyceride levels and low HDL [3]. Research on adolescents in Makassar shows that obese adolescents had higher triglyceride levels and lower HDL levels when compared to overweight adolescents. Obese adolescent boys had high triglyceride levels while more obese female adolescents had low HDL levels [7]. Similarly, another study reported that more boys had higher triglyceride levels than girls [8], [9]. As for HDL levels, it was found that male adolescents aged 16-19 years had lower HDL levels when compared to adolescent girls [10]. Another study found that low HDL levels were more common in children, adolescents, and adult males when compared to females [11]. In 
adolescent boys, obesity causes a decrease in the number of HDL subspecies [12].

Ratio of triglyceride/HDL is the ratio between the values of measurement of triglycerides to HDL. This ratio reflects the interactions between lipid fractions compared to only looking at triglyceride or HDL levels [13]. This ratio is related to disorders and diseases of metabolism. During the 20-year follow-up found that to group with high triglyceride/HDL ratio is likely to have hypertension when compared with the group that has low ratio triglyceride/HDL ratio [14].

There is a significant relationship between physical activity and obesity. Respondents who did not exercise in a regular basis may have a risk of obesity 1.35 times higher than their counterparts. In addition, respondents who do not exercise regularly tend to have a higher energy intake than those who exercise regularly [15]. It has been widely known that physical activity plays an important role in the prevention of obesity in children and adolescents [16]. Research in Turkey shows that men have higher physical activity scores than women [17]. Women are more sedentary than men [2]. Teenage boys look more moderate to heavy physical activity when compared to teenage girls, but the difference is not significant. Adolescent boys are more involved in physical activity when compared to adolescent girls [18]. However, a study in India found that there was no difference of physical activity by sex, including moderate-to-vigorous activity [19].

In Makassar, the number of obese adolescents has been increased significantly. This phenomenon has the potential to cause medical implications, such as an increased risk of adolescent obesity against cardiometabolic disease. Gender has been shown to play an important role in the risk of cardiometabolic disease through triglycerides, HDL, and physical activity. Therefore, this study will discuss the gender differences in the triglyceride/HDL ratio and physical activity in obese adolescents. This paper is expected to provide information for the development of appropriate interventions based on gender.

\section{Materials and Methods}

This study used a cross-sectional study design. This study was conducted at State Senior High School (SMA), namely SMA 12, SMA 13, and SMA 16 in Makassar City. Data collection was performed from September 3, 2019, to October 3, 2019. The population in this study was all adolescents aged 15-18 years in SMA 12, SMA 13, and SMA Negeri 16 Makassar. The target population is obese adolescents based on the screening performed before data collection. A simple random sampling method has been used to select participant of the study. The inclusion criteria were obese adolescent and willing to be measured and interviewed. If the students were absent at the time of data collection, they will be excluded in the study. The samples in this study were 93 students consisting of 54 students from SMA Negeri 12, 16 students from SMA Negeri 13, and 23 students from SMA Negeri 16 Makassar.

At the screening phase, we only measured those who are clinically or suspected to be overweight or obese and are willing to measure their weight and height. The research sample was measured by weight and height directly by researchers using digital weight scales and microtoise. We determine the status of obesity using body mass index for age z score (BAZ). Students' weight was measured using SECA digital weight scales. Students were asked to wear minimal clothes and they were not allowed to wear shoes or other things that might affect weight; the height of the sample is measured using microtoise. The tool is posted on the wall in a flat school area. Respondents were then asked to take off shoes and socks and not wear hats. Respondents were asked to stand up straight with their heels pressed against the wall and straight ahead. The height is then measured and read at the nearest decimal number.

Samples are asked to fill out a questionnaire that measures heavy physical activity (vigorous activity), moderate physical activity (moderate activity), walking activity, and sitting activity on someone in the past week using the International Physical Activity Questioner. Before the blood taken, the procedure has been clearly conveyed to the sample, including fasting for 10-12 h. Then with aseptic manner, $10 \mathrm{~mL}$ of the blood sample was for each student by a trained laboratory staff of Prodia. The blood was then stored in a cool box of $8^{\circ} \mathrm{C}$ and transported to the Prodia laboratory for further examination.

Triglycerides are a type of fat found in the blood. This type is the result of the body's work description of foods containing fat and cholesterol that have been consumed and entered the body, and also formed in the liver. In this study, triglycerides are categorized into two, namely normal and abnormal. Normal if the triglyceride level is $<150 \mathrm{mg} / \mathrm{dl}$ and abnormal if the triglyceride level is $>150 \mathrm{mg} / \mathrm{dl}$

HDL is the smallest and densest lipoprotein, containing the highest proportion of protein to cholesterol. In this study, HDL was categorized into two, namely normal and low. Normal if HDL levels in men> $40 \mathrm{mg} / \mathrm{dl}$ and women> $50 \mathrm{mg} / \mathrm{dl}$. Low if HDL levels in men $<40 \mathrm{mg} / \mathrm{dl}$ and women $<50 \mathrm{mg} / \mathrm{dl}$

The Triglyceride / HDL ratio is the result of a comparison of the laboratory value of triglycerides with high density lipoproteins [20]. In this study, the Triglyceride / HDL ratio was categorized into two, namely low and high. Low if the score of male respondents is $<3.5$ and the score of female respondents is $<2$. High if the score of male respondents is $>3.5$ and the score 
of female respondents is $>2$ [21]. Physical activity is any movement of the body that requires energy to do it. In this study it was categorized into 3, namely mild if the respondent's physical activity score was $<600$ MET minutes / week, moderate if the respondent's physical activity score was $>600$ to <3000 MET minutes / week and heavy if the respondent's activity score was $>3000$ MET minutes / week.

Data were analyzed using SPSS. We presented the data in the form of univariate and bivariate analysis. To examine the relationship between sex with triglyceride levels, HDL levels, and triglyceride/ HDL ratios, Chi-square test was used, while Fisher's exact test for examining the relationship between sex and physical activity.

\section{Results}

Table 1 shows that the sample in this study was generally male $(61.3 \%)$ and aged $>16$ years $(75.3 \%)$. Most fathers sample occupation is civil servants (PNS), which is $43 \%$ and the most occupation of mothers is as housewives (IRT), which is $41.9 \%$. Table 2 shows that the mean triglyceride is $124.19 \mathrm{mg} / \mathrm{dl}$, with a standard deviation of $+55.908 \mathrm{mg} / \mathrm{dl}$, the highest value is $283 \mathrm{mg} / \mathrm{dl}$ and the lowest value is $56 \mathrm{mg} / \mathrm{dl}$. The mean value for $\mathrm{HDL}$ is $44.19 \mathrm{mg} / \mathrm{dl}$, with a standard deviation of +8.16 , the highest value is $70 \mathrm{mg} / \mathrm{dL}$, and the lowest value is $31 \mathrm{mg} / \mathrm{dL}$. The triglyceride/HDL ratio score has a mean

Table 1: Characteristic respondents

\begin{tabular}{lll}
\hline Characteristics & $(\mathrm{n}=93)$ & $\%$ \\
\cline { 2 - 3 } & $\mathrm{n}$ & \\
\hline Sex & 57 & 61.3 \\
$\quad$ Male & 36 & 38.7 \\
$\quad$ Girl & & \\
Age & 23 & 24.7 \\
$\quad<16$ years old & 70 & 75.3 \\
$\quad \geq 16$ years old & & \\
Father's occupation & 2 & 2.2 \\
$\quad$ Daily labors & 1 & 1.1 \\
Medical doctors (GP) & 13 & 14.0 \\
Teachers & 2 & 2.2 \\
Private employees & 2 & 2.2 \\
Managers & 40 & 43.0 \\
Civil servants & 33 & 35.5 \\
$\quad$ Entrepreneurs & & \\
Mother's job & 2 & 2.2 \\
$\quad$ Midwives & 1 & 1.1 \\
Medical doctors (GP) & 17 & 18.3 \\
Teachers & 39 & 41.9 \\
Housewives & 2 & 2.2 \\
Farmers & 22 & 23.7 \\
Civil servants & 10 & 10.8 \\
$\quad$ Entrepreneurs & & \\
\hline
\end{tabular}

Table 2: Levels of TGL, HDL, ratio of triglyceride/HDL, and physical activity sample

\begin{tabular}{llll}
\hline Parameter & Mean \pm SD & Min & Max \\
\hline Triglyceride (mg/dL) & $124.19 \pm 55.908$ & 56 & 283 \\
HDL (mg/dL) & $44.19 \pm 8.16$ & 31 & 70 \\
Triglyceride/HDL ratio (score) & $2.94 \pm 1.50$ & 1.07 & 7.86 \\
Physical activity (METs) & $2809.8 \pm 2031.8$ & 405 & 8178 \\
\hline TGL: Triglycerides, HDL: High-density lipoprotein. & &
\end{tabular}

value of 2.94 with a standard deviation of + 1.50 , the highest value is 7.86 , and the lowest value is
1.07. Physical activity has a mean value of 2809.8 MET with a standard deviation +2031.8 , the highest value is $8178 \mathrm{MET}$, and the lowest value is $405 \mathrm{MET}$.

Table 3 shows that the mean value of triglycerides in obese men $(134.30 \mathrm{mg} / \mathrm{dl})$ is higher than in obese women $(103.8 \mathrm{mg} / \mathrm{dl})$. Mean $\mathrm{HDL}$ values in obese men $(42.65 \mathrm{mg} / \mathrm{dl})$ are lower than HDL values in obese women $(46.64 \mathrm{mg} / \mathrm{dl})$. The mean triglyceride/HDL ratio in men (3.39) is higher than in women (2.34). The mean value of physical activity in obese men (2825.8 MET) is higher than obese women (2800.3 MET).

Based on Table 4, it can be seen that triglyceride levels in obese adolescent boys (66.7\%) and obese adolescent girls (91.7) are still largely normal. Chisquare test value shows the $p=0.006$, which means that there is a relationship between sex with triglyceride levels in obese adolescents. In addition, it was also seen that HDL levels in obese male adolescents (56.1\%) and obese female adolescents $(77.8 \%)$ were also largely normal. Chi-square test value shows the value of $p=0.034$, which means that there is a relationship between sex with HDL levels. Instead, different results were found in the triglyceride/HDL ratio. The triglyceride/ HDL ratio in obese adolescent boys mostly has a low score $(61.4 \%)$, compared to obese adolescent girls whose scores are mostly high (55.6). Chi-square test value shows the value of $p=0.109$, which means that there is no gender relationship with the triglyceride/HDL ratio in obese adolescents. Physical activity in obese adolescent boys and obese adolescent girls is mostly moderate activity, namely $61.4 \%$ and $52.8 \%$. Fisher's exact test results showed a value of $p=0.339$, which means that there is no gender relationship with physical activity in obese adolescents.

\section{Discussion}

This research aimed to examine the relationship between sex and triglyceride levels, HDL, triglyceride/ HDL ratio, and physical activity among obese adolescents. Some studies in the literature have shown that there is a relationship between these variables, although the results have not been inconsistent.

This study found that high triglyceride levels were more common in obese adolescent boys (33.3\%) than obese adolescent girls (8.3\%). Chi-square test results showed $p=0.006$, which means that there is a relationship between sex with triglyceride levels in obese adolescents. The mean value of triglycerides is higher in men $(134.30+53.5 \mathrm{mg} / \mathrm{dl})$, whereas in women $(103.8+29.9 \mathrm{mg} / \mathrm{dl})$, this can be caused by different eating patterns.

Similarly, levels of HDL are low more common in obese boys $(43.9 \%)$ than girls $(22.2 \%)$. Chi-square 
Table 3: TGL, HDL, triglyceride/HDL ratio, and physical activity based on gender samples

\begin{tabular}{|c|c|c|c|c|c|c|}
\hline \multirow[t]{2}{*}{ Parameter } & \multicolumn{3}{|l|}{ Boys } & \multicolumn{3}{|l|}{ Girls } \\
\hline & Mean \pm SD & Min & $\operatorname{Max}$ & Mean \pm SD & Min & Max \\
\hline Triglyceride $(\mathrm{mg} / \mathrm{dL})$ & $134.30 \pm 53.5$ & 56 & 283 & $103.8 \pm 29.9$ & 59 & 184 \\
\hline $\mathrm{HDL}(\mathrm{mg} / \mathrm{dL})$ & $42.65 \pm 7.55$ & 31 & 63 & $46.64 \pm 8.59$ & 32 & 70 \\
\hline Triglyceride/HDL ratio (score) & $3.39 \pm 1.93$ & 1.26 & 12.25 & $2.34 \pm 0.98$ & 1.07 & 5.56 \\
\hline Physical activity (METs) & $2815.8 \pm 1767.5$ & 471 & 7070 & $2800.3 \pm 2419.3$ & 405 & 8178 \\
\hline
\end{tabular}

TGL: Triglycerides, HDL: High-density lipoprotein.

test value shows the value of $p=0.034$, which means that there is a relationship between sex with HDL levels. According to the result of HDL concentration by sex, this study found that the mean value of HDL in obese boys (42.65 $\mathrm{mg} / \mathrm{dL}$ ) was generally normal (normal range for boys $>40 \mathrm{mg} / \mathrm{dL}$ ). Although the value is lower than the HDL value in obese girls $(46.64 \mathrm{mg} / \mathrm{dL})$, which is generally higher but has not reached the normal HDL limit (normal range for girls $>50 \mathrm{mg} / \mathrm{dL}$ ).

HDL levels in women are higher than men. In a study in Korea, it was found that women had a mean HDL value of $46.3 \mathrm{mg} / \mathrm{dl}$, while men had a mean HDL of $43.8 \mathrm{mg} / \mathrm{dl}$ [22]. High levels of HDL in women explain why women have a lower risk of dying from cardiovascular disease [23]. The difference in HDL levels can be explained because women have the hormone estrogen. Estrogen is known to reduce fat accumulation activity in women [24]. A study found that HSD11B1SNP, which indirectly affects glucose and HDL metabolism in women, is likely to be under the regulation of the HSD11B1 gene associated with estrogen [25]. However, HDL levels decreased significantly in women who were exposed to passive smoking when compared to women who were not exposed. This was not found in men. Cigarette smoke can increase cardiovascular risk in adolescent girls [26].

Table 4: Relationship of TGL, HDL, triglyceride/HDL ratio, and physical activity based on gender samples

\begin{tabular}{|c|c|c|c|c|c|}
\hline \multirow[t]{2}{*}{ Parameter } & \multicolumn{2}{|c|}{ Male } & \multicolumn{2}{|c|}{ Girl } & \multirow[t]{2}{*}{$\mathrm{p}$} \\
\hline & $\mathrm{n}$ & $\%$ & $n$ & $\%$ & \\
\hline \multicolumn{6}{|l|}{ Triglycerides } \\
\hline Normal & 38 & 66.7 & 33 & 91.7 & \multirow[t]{2}{*}{$0.006^{*}$} \\
\hline High & 19 & 33.3 & 3 & 8.3 & \\
\hline \multicolumn{6}{|l|}{$\mathrm{HDL}$} \\
\hline Normal & 32 & 56.1 & 28 & 77.8 & \multirow[t]{2}{*}{$0.034^{*}$} \\
\hline Low & 25 & 43.9 & 8 & 22.2 & \\
\hline \multicolumn{6}{|c|}{ Triglyceride/HDL ratio } \\
\hline Low & 35 & 61.4 & 16 & 44.4 & \multirow[t]{2}{*}{$0.109^{*}$} \\
\hline High & 22 & 38.6 & 20 & 55.6 & \\
\hline \multicolumn{6}{|c|}{ Physical activity } \\
\hline Low & 3 & 5.3 & 5 & 13.9 & \multirow[t]{3}{*}{$0.339^{\star \star}$} \\
\hline Moderate & 35 & 61.4 & 19 & 52.8 & \\
\hline High & 19 & 33.3 & 12 & 33.3 & \\
\hline
\end{tabular}

Obesity is closely related to the risk of heart disease. Myocardial metabolic responses in men and women to obesity are not exactly the same. Obesity and gender trigger myocardial blood flow and MVO2 is strongly associated with myocardial substrate metabolism. Gender differences in myocardial metabolism may affect development or adaptation to obesity related to heart disease [27]. Male gender, family history of obesity, and low HDL levels correlate with the incidence of metabolic syndrome [28].

This study shows that the triglyceride/HDL ratio in obese adolescent boys mostly has a low score
(61.4\%), compared to obese adolescent girls whose scores are mostly high (55.6\%). The mean triglyceride/ HDL ratio in men [3], [37] is higher than in women [2], [34]. The reason that the triglyceride/HDL ratio scores in men lower than in women is probably related to the standard used, where men have a standard score of 3.5 and women [2]. Thus, the triglyceride/HDL ratio score does not describe each component of cholesterol, but rather the contraction between the two. In spite of the men have higher triglycerides and lower HDL, most of the triglyceride/HDL ratio scores is actually low. If the triglyceride/HDL ratio scores in boys are mostly low, it does not mean that they are free from the risk of metabolic syndrome. Obese boys and girls are equally at risk of metabolic syndrome.

The triglyceride/HDL ratio is a good marker of atherogenic lipid abnormalities. In addition, this ratio also correlates with the incidence of insulin resistance, increased risk of cardiovascular disease, and metabolic syndrome [29], [30]. According to one study, the triglyceride/HDL ratio can be used to identify adolescents at risk for obesity, dyslipidemia, hypertension, and metabolic syndrome [31]. The other studies have shown that triglyceride/HDL ratio is the best marker for identifying individuals at risk of metabolic syndrome compared to other ratios [32].

This study shows that physical activity in obese adolescent boys and obese adolescent girls is mostly moderate activity, namely $61.4 \%$ and $52.8 \%$. Fisher's exact test results showed a value of $p=0.339$, which means that there is no gender relationship with physical activity in obese adolescents. The mean value of physical activity in obese men (2825.8 MET) is higher than obese women (2800.3 MET).

The results of this study are different from research conducted by Taber, et al., 2016. Taber's research found a relationship between physical activity and gender. Measurement of physical activity includes total physical activity in the past year and the number of days of moderate to heavy physical activity in the past week [33]. Research in Turkey shows that men have higher physical activity scores than women [17]. A study found that women were more likely to be sedentary than men [2]. Teenage boys look more moderate to heavy physical activity when compared to young women, although the difference is not significant. Other studies have found that more boys are involved in physical activity than girls [18].

Physical activity plays an important role in the prevention of obesity in children and adolescents [16]. There is a role for physical activity in adolescent 
mental health. Adolescent girls report lower mental health and less physical activity when compared to adolescent boys [34]. It is necessary to encourage obese adolescents to do physical activity so that not only improve their nutritional status but also maintain mental health. Physical activity is very important to maintain the physical and mental health of obese adolescents.

This research contributes to preventing heart and blood vessel disease early on by providing a basis for developing interventions that are gender compatible. The best way to find out who is at high risk is through early prevention screening. This helps reduce risk in adolescents so that interventions can be developed that can reduce these risks [35]. Some researchers suggest that the prevention of heart and blood vessel disease is done by identifying risk factors and behavior early on [36].

\section{Recommendation}

Efforts should be made to reduce the risk level of obese adolescents to the risk of metabolic syndrome and cardiovascular disease, including physical activity as physical activity can maintain the physical and mental of obese adolescents.

\section{Conclusion}

There was a relationship between gender and triglyceride levels $(p=0.006)$ and HDL levels $(p=0.034)$. However, no relationship was found between the Triglyceride / HDL ratio $(p=0.109)$ and physical activity $(p=0.339)$ in obese adolescents in Makassar City.

\section{References}

1. Mahfouz AA, Shatoor AS, Khan MY, Daffalla AA, Mostafa OA, Hassanein MA. Nutrition, physical activity, and gender risks for adolescent obesity in Southwestern Saudi Arabia. Saudi J Gastroenterol. 2011;17(5):318-22. https://doi. org/10.4103/1319-3767.84486

\section{PMid:21912058}

2. Hussain Z, Mehmood S, Hussain B, Ali I, Afzal S. Prevalence of obesity on gender base at Gilgit City Pakistan. Adv Obes Weight Manag Control. 2017;6(2):59-62. https://doi.org/10.15406/ aowmc.2017.06.00149

3. Negash S, Agyemang C, Matsha TE, Peer N, Erasmus RT, Kengne AP. Differential prevalence and associations of overweight and obesity by gender and population group among school learners in South Africa: A cross-sectional study. BMC Obes. 2017;4:29. https://doi.org/10.1186/s40608-017-0165-1

PMid:28725448
4. Lissau I. Body mass index and overweight in adolescents in 13 European Countries, Israel, and the United States. Arch Padiatr Adolesc Med. 2004;158(1):27-33. https://doi.org/10.1001/ archpedi.158.1.27

PMid:14706954

5. Lobstein T, Frelut ML. Prevalence of overweight among children in Europe. Obes Rev. 2003;4(4):195-200. https://doi. org/10.1046/j.1467-789x.2003.00116.x

PMid: 14649370

6. Nieves DJ, Cnop M, Retzlaff B, Walden CE, Brunzell JD, Knopp RH, et al. The atherogenic lipoprotein profile associated with obesity and insulin resistance is largely attributable to intra-abdominal fat. Diabetes. 2003;52(1):172-9. https://doi. org/10.2337/diabetes.52.1.172

PMid:12502509

7. Jafar N, Kurniati Y, Indriasari R, Syam A, Arviani A, Patintingan M Analysis of triglyceride and high-density lipoprotein levels in overweight adolescents. Pak J Nutr. 2019;18(8):778-82. https:// doi.org/10.3923/pjn.2019.778.782

8. Sinsanta S, Halim SL, Iskandar I. Correlation of body mass index and blood triglyceride levels of UKRIDA medical faculty students for the 2004/2005 academic year. Med Med J. 2006;14(38):1-8. https://doi.org/10.36452/jkdoktmeditek.v14i38.178.

9. Sinaga I, Tobing CJ, Ardinata D. Description of triglyceride levels in obese adults in pasar II Tanjung Suri Medan. J Methodist Med. 2018;11(2):215-8.

10. Nguyen D, Kit B, Carrol M. Abnormal cholesterol among children and adolescents in the United States, 2011-2014. NCHS Data Brief. 2015;228:1-8.

PMid:26727279

11. Aranmolate A. Comparison of abnormal cholesterol in children, adolescent and adults in the United States, 2011-2014: Review. Eur J Environ Public Health. 2017;1(1):1-8. https://doi. org/10.20897/ejeph/75156

12. Shah AS, HeinkA, Sexmith H, Dolan L, Gordon S, Khoury J, et al. Obesity drives the decline in large HDL subspecies among male adolescent. Arterioscler Thromb Vasc Biol. 2017;37(1):A220.

13. Dobiásová $M$, Frohlich J. The plasma parameter log (TG/ HDL-C) as an atherogenic index: Correlation with lipoprotein particle size and esterification rate in apoB-lipoprotein-depleted plasma (FER(HDL)). Clin Biochem. 2001;34:583-8. https://doi. org/10.1016/s0009-9120(01)00263-6

PMid:11738396

14. Yeom H, Kim HC, Lee JM, Jeon Y, Suh I. Triglyceride to high density lipoprotein cholesterol ratio among adolescents is associated with adult hypertension: The Kangwha study. Lipids Health Dis. 2018;17:212. https://doi.org/10.1186/ s12944-018-0861-y

PMid:30200983

15. Mustelin L, Silventoinen K, Pietiläinen K, Rissanen A, Kaprio J. Physical activity reduces the influence of genetic effects on BMI and waist circumference: A study in young adult twins. Int J Obes (Lond). 2009;33(1):29-36. https://doi.org/10.1038/ijo.2008.258 PMid: 19048013

16. Hills AP, King NA, Armstrong TP. The contribution of physical activity and sedentary behaviours to the growth and development of children and adolescents: Implications for overweight and obesity. Sport Med. 2007;37(6):533-45. https:// doi.org/10.2165/00007256-200737060-00006 PMid: 17503878

17. Caglar E, Aşçı FH. Gender and physical activity level differences in physical self-perception of university students: A case of Turkey. Int J Sport Psychol. 2006;37:58-74.

18. Santos P, Guerra S, Ribeiro JC, Duarte JA, Mota J. Age and gender-related physical activity. A descriptive study in 
children using accelerometry. J Sports Med Phys Fitness. 2003;43(1):85-9.

19. Raskind I, Patil SS, Cunningham SA, Kramer MR. Physical activity patterns among Indian adolescent: Independent and join association of gender and socioeconomic status. Circulation. 2019;139(Suppl 1):322. https://doi.org/10.1161/circ.139. suppl_1.p322

20. Pacifico L, Bonci E, Andreoli G, Romaggioli S, Di Miscio R, Lombardo CV, et al. Association of serum triglyceride-to-HDL cholesterol ratio with carotid artery intima-media thickness, insulin resistance and nonalcoholic fatty liver disease in children and adolescents. Nutr Metab Cardiovasc Dis. 2014;24(7):73743. https://doi.org/10.1016/j.numecd.2014.01.010 PMid:24656140

21. Sung KC, Reaven G, Kim S. Ability of the plasma concentration ratio of triglyceride/high-density lipoprotein cholesterol to identify increased cardio-metabolic risk in an East Asian population. Diabetes Res Clin Pract. 2014;105(1):96-101. https://doi. org/10.1016/j.diabres.2014.04.021

22. Kim HJ, Park HA, Cho YG. Gender difference in the level of HDL cholesterol in Korean adult. Korean J Fam Med. 2011;32(3):17381. https://doi.org/10.4082/kjfm.2011.32.3.173

23. Mascitelli L, Pezzetta F. High-density lipoprotein cholesterol and sex difference in coronary heart disease risk. Am J Med. 2006;119(5):e17. https://doi.org/10.1016/j.amjmed.2005.10.044

24. Rossouw JE. Hormones, genetic factors, and gender differences in cardiovascular disease. Cardiovasc Res. 2002;53(3):550-7. https://doi.org/10.1016/s0008-6363(01)00478-3

25. Turek LV. Gender-dependent association of HSD11B1 single nucleotide polymorphisms with glucose and HDL-C levels. Genet Mol Biol. 2014;37(3):490-5. https://doi.org/10.1590/ s1415-47572014000400003

26. Le-Ha C, Beilin LJ, Burrows S, Huang RC, Oddy $\mathrm{WH}$, Hands B, et al. Gender difference in the relationship between passive smoking exposure and HDL-cholesterol levels in late adolescence. J Clin Endocrinol Metab. 2013;98(5):2126-35. https://doi.org/10.1210/jc.2013-1016

27. Peterson LR, Soto PF, Herrero P, Mohammed BS, Avidan MS, Schechtman KB, et al. Impact of gender on the myocardial metabolic response to obesity. JACC Cardiovasc Imaging. 2008;1(4):424-33. https://doi.org/10.1016/j.jcmg.2008.05.004 PMid: 19356462

28. Mahbuba S, Mohsin F, Rahat F, Nahar J, Begum T, Nahar N. Descriptive epidemiology of metabolic syndrome among obese adolescent population. Diabetes Metab Syndr Clin Res Rev. 2018;12(3):369-74. https://doi.org/10.1016/j.dsx.2017.12.026
29. He F, Rodriguez-Colon S, Fernandez-Mendoza J, Vgontzas AN, Bixler EO, Berg A, et al. Abdominal obesity and metabolic syndrome burden in adolescents--Penn State children cohort study. J Clin Densitom. 2015;18(1):30-6. https://doi. org/10.1016/j.jocd.2014.07.009

PMid:25220887

30. Wu H, Xiong L, Xu Q, Wu J, Huang R, Guo Q, et al. Higher serum triglyceride to high-density lipoprotein cholesterol ratio was associated with increased cardiovascular mortality in female patients on peritoneal dialysis. Nutr Metab Cardiovasc Dis. 2015;25(8):749-55. https://doi.org/10.1016/j. numecd.2015.05.006

31. Quijada Z, Paoli M, Zerpa Y, Camacho N, Cichetti R, Villarroel V, et al. The triglyceride/HDL-cholesterol ratio as a marker of cardiovascular risk in obese children; association with traditional and emergent risk factors. Pediatr Diabetes. 2008;9(5):464-71. https://doi.org/10.1111/j.1399-5448.2008.00406.x PMid: 18507788

32. Gasevic D, Frohlich J, Mancini GJ, Lear SA. Clinical uselfulness of lipid ratios to identify men and women with metabolic syndrome: A cross-sectional study. Lipids Health Dis. 2014;13:159. https://doi.org/10.1186/1476-511x-13-159 PMid:25300321

33. Taber DR, Robinson WR, Bleich SN, Wang YC. Deconstructing race and gender differences in adolescent obesity: Oaxacablinder decomposition. Obesity (Silver Spring). 2016;24(3):71926. https://doi.org/10.1002/oby.21369

34. Halliday A, Kern ML, Turnbull DA. Can physical activity help explain the gender gap in adolescent mental health? A crosssectional exploration. Ment Health Phys Act. 2019;16:8-18. https://doi.org/10.1016/j.mhpa.2019.02.003

35. Bloetzer C, Bovet P, Suris JC, Simeoni U, Paradis G, Chiolero A. Screening for cardiovascular disease risk factors beginning in childhood. Public Health Rev. 2015;36:9. https://doi.org/10.1186/ s40985-015-0011-2

36. Chen $X$, Wang $Y$. Tracking of blood pressure from childhood to adulthood: A systematic review and meta-regression analysis. Circulation. 2008;117(25):3171-80. https://doi.org/10.1161/ circulationaha.107.730366 PMid: 18559702

37. Woudberg NJ, Goedecke JH, Blackhurst D, Frias M, James R, Opie LH, et al. Association between ethnicity and obesity with high-density lipoprotein (HDL) function and subclass distribution. Lipids Health Dis. 2016;15:92. https://doi.org/10.1186/ s12944-016-0257-9

PMid:27169717 